\title{
Consistent weight loss linked to higher meal frequency
}

\begin{abstract}
Obesity is a very interesting topic of study as it is directly related to human disease. Recently, we have reported that successful weight loss programs should consider the optimal timing for the brain control of weight-presetting, the fundamental of the "Lipostat theory". This previous study was the first reported long-term human self-experiment involving successful weight loss, metabolic adaptation and weightpresetting, consistent with this theory while raising new concepts, ideas and setting up the bases for further investigations. One of such investigations is reported in this review. An inverse relationship between people's habitual frequency of eating and body weight was consistently observed, suggesting that "snack-eating" may help to avoid obesity, further supporting other previously published meal frequency studies.
\end{abstract}

Volume 9 Issue I - 2019

\author{
JM Peregrin-Alvarez \\ Scientist and CEO at Virtual Personal Trainer, Granada, Spain \\ Correspondence: JM Peregrin-Alvarez, Scientist and CEO at \\ Virtual Personal Trainer, Granada, Spain, \\ Email josem.peregrin@gmail.com
}

Received: January 24, 2019 | Published: February 26, 2019

Keywords: obesity, overweight, ideal weight, weight loss, weight management, meal frequency, lipostat theory

Abbreviations: BMI: body mass Index; HA: healthiest area; IW: ideal weight; M: milestone; MF: meal frequency; WG: weight gain; WL: weight loss

\section{Introduction}

Obesity has been a global topic of concern for a long time as it is directly linked to human disease, causing more than 3.4 million deaths all around the word. ${ }^{1-3}$ To avoid this serious health issue, successful weight management programs should consider the required timing for feedback signals originating in adipose tissue to influence the brain centres that control eating behavior and activity (metabolic and motor), the fundamental of the "Lipostat theory", ${ }^{4}$ which has been demonstrated for the very first time in humans in our previous study. ${ }^{5}$ This theory refers to the control of long term appetite, responsible for the control of body weight. As fat deposits accumulate, satiety signals are sent to the hypothalamus in response in an attempt to suppress the feeling of hunger and maintain a constant body weight. The study showed that HA was more efficient than simple BMI measurements, and the subject under study, originally obese, able to successfully reach and maintain an HA category (IW) over the years. New concepts and ideas were raised by that study, setting up the bases for further experimental validations. Thus, continuing with that study, the purpose of this case report is to present and discuss our selfexperimental research on meal frequency over a long period of time with respect to changes in body weight.

\section{Materials and methods}

A single individual was subjected to case study. The values of BMI Normal category were transformed into IW, based on height and weight, and further sub-categorized ${ }^{5}$ into the following categories: HA, BMI normal; and BMI Under weight. Two MF plans repetitions were implemented over a period of more than one year, organized into four milestones (M1-M4): M1, 16 weeks ( 4 months) following a 3 meals/day plan; M2, same period of time following a 6 meals/ day plan; and M3 and M4, by repeating M1 and M2 experiment under the same conditions. All milestones were energy balanced for weight maintenance purposes (calorie in: $2300 \mathrm{kcal} /$ day; calorie out: $500 \mathrm{kcal} /$ day). Any choice of food/activity was allowed following basic nutrition guidelines. ${ }^{7}$ HA and energy balance calculations, as well as calorie in (meals)/out (workouts) self-monitoring was done by mobile apps. ${ }^{8}$

\section{Results and discussion}

Starting at weight 64, $5 \mathrm{~kg}$ (Figure 1) (height $178 \mathrm{~cm}$ ) (HA; BMI category normal), a consistent and constant WL was recorded during M1 and M3 (average WL rate $\sim 0.25 \mathrm{~kg} /$ week), and a WG (average WG rate $\sim 0.3 \mathrm{~kg} /$ week) during M 2 and M 4 . This represents an average total WL of $4.4 \mathrm{~kg}$ during M1 and M3, and an average total WG of $4.8 \mathrm{~kg}$ during M2 and M4. Milestones implementation provided with a robust and efficient way of gradually controlling a person's weight while costing less than conventional treatments. ${ }^{9}$ Small up/down peaks along the WL/WG lines correspond to metabolic adaptations. Interestingly, the HA trend was always shortly and consistently recovered after switching from a 6 to anusual 3 meals/day plan. These findings suggest WL due to a higher MF under controlled energy balance. This consistent inverse relationship between frequency of eating and body weight was observed by self-experimental validation (experimentation in which the experimenter conducts the experiment on her- or himself) and over a long period of time (more than one year), further supporting previous short-term MF epidemiological studies. ${ }^{6,10}$ Thus, our study suggest that "snack-eating" or small frequent meals, also referred to as grazing, picking or nibbling, may help body weight control, thus helping to avoid obesity and the implementation of effective weight management programs. However, since only one subject was subjected to study our conclusions should be taken with caution. 


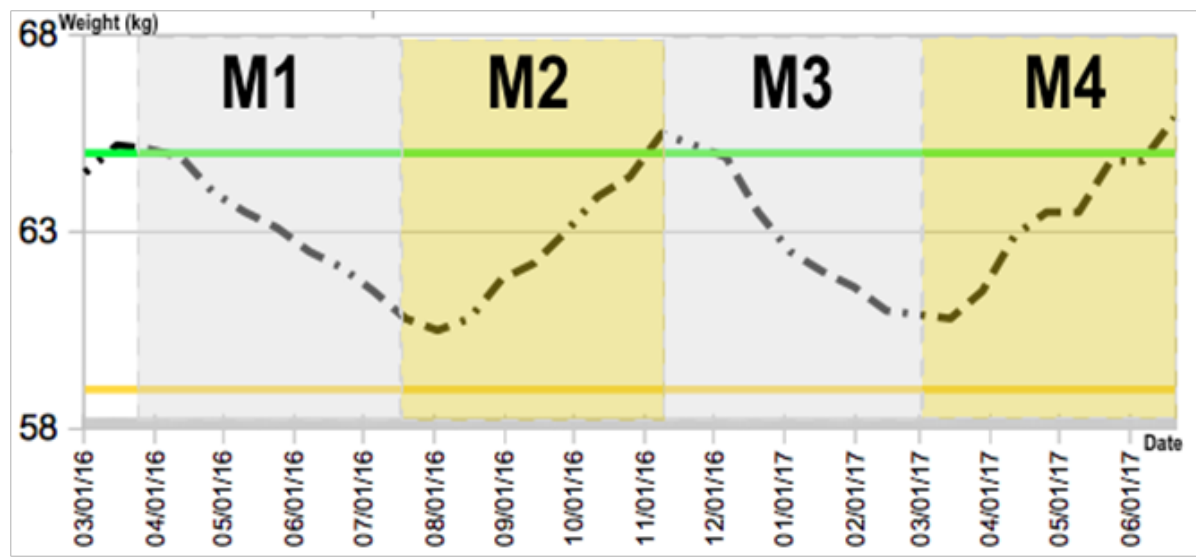

Figure I MF and weight control

Light grey coloured areas (MI/M3) correspond to 6 meals a day MF plans, and yellow areas (M2/M4) to 3 meals a day MF plans. The lower orange line represents the Underweight BMI line for the subject under study, and the upper green line represents HA (the healthiest weight area). The dashed black line shows consistent WL over MI/M3, and WG over M2/M4, related to MF. The consistent more than one year long pattern was observed throughout the complete duration of the self-experiment. A low HA-presetting was chosen by personal preference, suggesting that a personal control of body weight is possible after a successful weight-presetting, further supporting our previous findings. ${ }^{5}$

\section{Conclusion}

It has been hypothesized that eating small frequent meals enhances fat loss and helps to achieve better weight maintenance. A number of observational studies lend support to this hypothesis, with an inverse relationship noted between the frequency of eating and adiposity. ${ }^{6,10}$ However, these studies were performed over short periods of time, thus being questioned or considered weak by other conflicting studies. ${ }^{11-13}$ Our study represents the first successfully consistent long-term weight control self-experiment suggesting that "snack-eating" may help WL programs, thus helping to avoid obesity/overweight while controlling cholesterol levels and reducing cardiac risk. ${ }^{14}$ Proposed mechanisms that could explain this phenomenon include the favourable effects of increased MF on improved glucose homeostasis ${ }^{15-17}$ and increase in the thermal effect of feeding. ${ }^{18,19}$ Furthermore, frequent eating, either regular meals or between-meal snacks, may prevent from overeating at mealtime (appetite control). ${ }^{20-21}$ People eating only a few times a day have elevated 24-hour insulin levels. High insulin levels promote storing energy in body fat; and high insulin level is also a marker for heart disease risk. Moreover, once again, we have demonstrated the affectivity of combining technology and personal science. Mobile technology allowed a close interaction, autonomy and help motivation. ${ }^{5}$ This study set up the bases for the systematic implementation of efficient weight management programs. With sufficient funding these results can be adapted and reproduced on larger groups. Future studies should be able to further validate these results and answering some interesting questions raised here such the role of culture in body weight as MF might be determined by certain cultures. $^{23-30}$

\section{Acknowledgments}

None.

\section{Conflicts of interest}

The authors declared there is no conflict of interest.

\section{References}

1. Finucane MM, Stevens GA, Cowan MJ, et al. National, regional, and global trends in body-mass index since 1980: systematic analysis of health examination surveys and epidemiological studies with 960 country-years and 9• 1 million participants. Lancet. 2011;377(9765):557-567.
2. Ng M, Fleming T, Robinson M, et al. Global, regional, and national prevalence of overweight and obesity in children and adults during 1980-2013: a systematic analysis for the Global Burden of Disease Study. Lancet. 2014;384(9945):766-781.

3. Kelishadi R. Childhood overweight, obesity, and the metabolic syndrome in developing countries. Epidemiologic Rev. 2007;29(1):62-76.

4. Kennedy GC. The role of depot fat in the hypothalamic control of food intake in the rat. Proc R Soc Lond Biol. 1953;140:579-592.

5. Peregrin-Alvarez JM. Self-Experiencing "The Healthiest Weight". $J$ Obes Overweig. 2017;3(1):101.

6. Fabry P. The frequency of meals: its relation to overweight, hypercholesterolaemia, and decreased glucose tolerance. Lancet. 1964;2:614-615.

7. U.S. Department of Health and Human Services and U.S. Department of Agriculture (2015-2020) Dietary Guidelines for Americans. 8th ed.

8. Peregrin-Alvarez JM. Long-Term Weight Loss by Mobile App: Current Status and Future Perspectives. EC Nutrition SI. 2017;01:41-46.

9. Jakicic JM, Tate DF, Lang W, et al. Effect of a Stepped-Care Intervention Approach on Weight Loss in Adults: The Step-Up Study Randomized Trial. JAMA. 2012;307(24):2617-2626.

10. Summerbell CD, Moody RC, Shanks J, et al. Relationship between feeding pattern and body mass index in 220 free-living people in four age groups. Eur J Clin Nutr.1996;50:513-519.

11. Bellisle F, McDevitt R, Prentice AM. Meal frequency and energy balance. Br J Nutr. 1997;77(1):S57-70.

12. Cameron JD, Cyr MJ, Doucet E. Increased meal frequency does not promote greater weight loss in subjects who were prescribed an 8-week equi-energetic energy-restricted diet. Br J Nutr. 2010;103(8):1098-1101.

13. Schoenfeld BJ, Aragon AA, Krieger JW. Effects of meal frequency on weight loss and body composition: a meta-analysis. Nutr Rev. 2015;73(2):69-82.

14. Titan SM, Bingham S, Welch A, et al. Frequency of eating and concentrations of serum cholesterol in the Norfolk population of the European prospective investigation into cancer (EPIC-Norfolk) (Cross sectional study). BMJ 2001;323(7324):1286-1288.

15. Jenkins DJ. Metabolic advantages of spreading the nutrient load: effects of increased meal frequency in non-insulin-dependent diabetes. $\mathrm{Am} \mathrm{J}$ Clin Nutr. 1992;55(2):461-467. 
16. Jenkins DJ, Wolever TM, Vuksan V, et al. Nibbling versus gorging: metabolic advantages of increased meal frequency. $N$ Engl $J$ Med.1989;321(14):929-934.

17. Jette Bertelsen, Christian Christiansen, Claus Thomsen, et al. Effect of meal frequency on blood glucose, insulin, and free fatty acids in NIDDM subjects. Diabetes Care. 1993;16(1):4-7.

18. Kinabo JLD, Durnin JVGA. Effect of meal frequency on the thermic effect of food in women. Eur J Clin Nutr. 1990;44:389-395.

19. Tai MM, Castillo P, Pi-Sunyer FX. et al. Meal size and frequency: effect on the thermic effect of food. Am J Clin Nutr. 1991;54(5):783-787.

20. Speechly DP, Buffenstein R. Greater appetite control associated with an increased frequency of eating in lean males. Appetite. 1999;33(3):285297.

21. Speechly DP, Rogers GG, Buffenstein R. Acute appetite reduction associated with an increased frequency of eating in obese males. Int $J$ Obes Relat Metab Disord. 1999;23(11):1151-1159.

22. Smeets AJ \& Westerterp-Plantenga MS. Acute effects on metabolism and appetite profile of one meal difference in the lower range of meal frequency. Br J Nutr. 2008;99(6):1316-1321.

23. Nangel M Lindberg, Victor J. Stevens, Ruben O Halperin. Weight-Loss Interventions for Hispanic Populations: The Role of Culture. Journal of Obesity. 2013:542736
24. Fábry P, Hejda S, Cerný K et al. Effect of meal frequency in schoolchildren: changes in weight-height proportion and skinfold thickness. American Journal of Clinical Nutrition. 1966;18:358-361.

25. Fabry P, Tepperman J. Meal frequency - a possible factor in human pathology. American Journal of Clinical Nutrition.1970;23:1059-1068.

26. Hejda S, Fabry P. Frequency of food intake in relation to some parameters of the nutritional status. Nutrition Dieta. 1964;6:216-221.

27. Charzewska J. Relationship between obesity or overweight development and the frequency of meals, their distribution during the day and consumption of atherogenic food products. Zywienie Czlowieka. $1981 ; 8: 217-227$.

28. Metzner HL, Lamphiear DE, Wheeler $\mathrm{NC}$ et al. The relationship between frequency of eating and adiposity in adult men and women in the Tecumseh Community Health Study. American Journal of Clinical Nutrition. 1977;30(5):712-715.

29. Edelstein SL et al. Increased meal frequency associated with decreased cholesterol concentrations; Rancho Bernardo, CA, 1984-1 987. Am J Clin Nutr. 1992;55(3):664-669.

30. Kant AK. Frequency of eating occasions and weight change in NHANES I Epidemiologic Follow-up Study. Int J Obes Relat Metab Disord. $1995 ; 19(7): 468-474$. 